\title{
In vitro Anti-mycobacterial activity of selected medicinal plants against Mycobacterium tuberculosis and Mycobacterium bovis Strains
}

\author{
Abdella Gemechu1*, Mirutse Giday ${ }^{2}$, Adane Worku $^{2}$ and Gobena Ameni ${ }^{2}$
}

\begin{abstract}
Background: Tuberculosis (TB) is a global burden with one -third of the world's population infected with the pathogen Mycobacterium tuberculosis complex and annually 1.4 million deaths occur due to the disease. This high incidence of infection and the increased rate of multi-drug resistant and extensively-drug resistant strains of the organism further complicated the problem of TB control and have called for an urgent need to develop new anti-TB drugs from plants. In this study, the in vitro activity of root of Calpurnia aurea, seeds of Ocimum basilicum, leaves of Artemisia abyssinica, Croton macrostachyus, and Eucalyptus camaldulensis were evaluated against $M$. tuberculosis and M. bovis strains.
\end{abstract}

Methods: Five Ethiopian medicinal plants, root of Calpurnia aurea, seeds of Ocimum basilicum, leaves of Artemisia abyssinica, Croton macrostachyus, and Eucalyptus camaldulensis used locally for the management of TB. They were investigated for in vitro antimycobacterial activity against M. tuberculosis and M. bovis strains. $80 \%$ methanolic extracts of the plant materials were obtained by maceration. The antimycobacterial activity was determined using 96 wells of microplate with the help of visual Resazurin Microtiter Assay.

Results: The crude $80 \%$ methanolic extracts of the root of C. aurea, seeds of O. basilicum, and leaves of A. abyssinica, C. macrostachyus, and E. camaldulensis had anti-mycobacterial activity with minimum inhibitory concentration (MIC) ranging from $6.25-100 \mu \mathrm{g} / \mathrm{mL}$. The MIC of $80 \%$ methanol extracts in the order mentioned above ranged $25-100 \mu \mathrm{g} / \mathrm{ml}$ and $12.5-75 \mu \mathrm{g} / \mathrm{mL}, 25-100 \mu \mathrm{g} / \mathrm{mL}$ and $25-50 \mu \mathrm{g} / \mathrm{mL}, 6.25-50 \mu \mathrm{g} / \mathrm{mL}$ and $12.5-50 \mu \mathrm{g} / \mathrm{mL}, 12.5-100 \mu \mathrm{g} / \mathrm{mL}$ and $18.25-50 \mu \mathrm{g} / \mathrm{mL}$ and $6.25-50 \mu \mathrm{g} / \mathrm{mL}$ and $12.5-50 \mu \mathrm{g} / \mathrm{mL}$, respectively for M. tuberculosis and $M$. bovis strains.

Conclusions: The results support the local use of these plants in the treatment of TB and it is suggested that these plants may have therapeutic value in the treatment of TB. However, further investigations are needed on isolating chemical constituents responsible for eliciting the observed activity in these plants.

Keywords: Antimycobacterial activity, Medicinal plants, MIC, REMA, M. tuberculosis \& M. bovis strains, Ethiopia

\section{Background}

Tuberculosis (TB) is caused by a set of closely related mycobacterial strains such as Mycobacterium tuberculosis, M. bovis, $M$. africanum and others, known collectively as the M. tuberculosis complex (MTC) [1]. Currently about one -third of the world's population is assumed to be infected with the tubercle bacillus [2,3]. It is responsible for 1.4 million deaths per a year [4]. Moreover, up to 50

\footnotetext{
* Correspondence: abdgemechu@gmail.com

'Department of Medical Laboratory Sciences, College of Health and Medical Science, Haramaya University, Harar, Ethiopia

Full list of author information is available at the end of the article
}

million people are said to be infected with drug-resistant forms of TB from which about 500,000 cases of multidrug resistant (MDR) TB worldwide per a year [5].

Management of TB/MDR-TB patient requires intense multi-chemotherapy for at least six months to two years. It is very hurtful to a patient's health due to high levels of drug toxicity and its adverse effects [6-8]. The emergence of MDR TB and extensively-drug resistant (XDR) TB to the medicines now in use makes urgent search for new anti-TB agents worldwide $[9,10]$. Medicinal plants offer a great hope to overcome these needs because of their chemical diversity and their significant role in the drug 
sighting and development [11]. They are also recognized as a useful source of highly active antimycobacterial metabolites [12].

In Ethiopia there are many plant species reported to be used traditionally to treat $\mathrm{TB}$ and respiratory tract infections. For instances, leaves and fruits of Allium ursinum were locally used for the treatment of bronchitis and $\mathrm{TB}$ respectively in Central Zone of Tigray [13]. It was also reported that locally available plant species such as Croton macrostachyus and Oenanthe procumbens in Farta wereda of Amhara region [14] and Arisaema schimperianum around Bale mountains national park [15] are to used to treat $\mathrm{TB}$ respectively. Likewise, roots of Calpurnia aurea are used for lung TB [16]. Additionally it was reported that fruits/seeds of Ocimum basilicum and Ocimum americanum, leaves of Eucalyptus camaldulensis, Artemisia afra and Artemisia abyssinica are used for cough and TB [17]. Leaves of Aloe pubescens, root of Indigofera amorphoides and Psydrax schimperiana are reported to be some of the medicinal plants locally used to treat TB and other respiratory illness and other diseases [18]. Moreover, in Chifra District, Afar region, it was reported that Kanahia laniflora and Aloe species were locally used for treatment of TB [19]. However, their efficacy remains unknown. Thus, the aim of this study was to evaluate the in vitro anti-mycobacterial activity of root of Calpurnia aurea, seeds Ocimum basilicum, leaves of Artemisia abyssinica, Croton macrostachyus, and Eucalyptus camaldulensis against M. tuberculosis and M. bovis strains.

\section{Methods}

\section{Study design}

This study was conducted at Aklilu Lemma Institute of Pathobiology (ALIPB), Addis Ababa University (AAU) using an experimental study design. Five plant species, namely C. aurea, O. basilicum, A. abyssinica, C. macrostachyus, and $E$. camaldulensis were selected for their in vitro activity test against $M$. tuberculosis and M. bovis strains. Susceptibility tests and MIC of the extracts were determined using Resazurin Microtiter Assay (REMA). Rifampicin was used as positive control while drug and extract free medium were used as negative controls.

\section{Collection of plants materials}

The leaves of C. macrostachyus, roots of C. aurea, and seeds of $O$. basilicum were collected from Addis Ababa. Leaves of E. camaldulensis, and A. abyssinica were collected from Harar (525 km East of Addis Ababa) and Muka Turi (Selale/North Shoa Zone) $80 \mathrm{~km}$ north of Addis Ababa, respectively (Table 1). The identities of each plant specimen were identified by Dr. Mirutse Giday (a botanist) at the Endod and Other Medicinal Plants Research Unit, ALIPB. A voucher specimen of each plant was deposited at the Endod and Other Medicinal Plants Research Unit, with voucher numbers AG-01 (O. basilicum), AG-02 (C. macrostachyus), AG-03 (C. aurea), AG-04 (E. camal dulensis), and AG- 05 (A. abyssinica). All parts of the plant materials were made to become dry in an open air and protected from direct exposure to sunlight. The dried plant materials were separately powdered to suitable size by using mortar and pestle, and then made ready for extraction.

\section{Preparation of the extract}

The powdered plant materials were weighed using analytical balance and prepared for solvent extraction. The crude $80 \%$ methanolic extracts of the plant materials were obtained by maceration. The total crude $80 \%$ methanolic extracts were obtained by soaking powdered plant material (about $50 \mathrm{~g}$ ) in $400 \mathrm{~mL}$ methanol for $48-$ $72 \mathrm{~h}$ on an orbital shaker [20]. Extracts were filtered using Whatman No.1 filter paper and concentrated using a rotary evaporator (Laborota 4000, SN 090816862, Germany) in a water bath set at $40^{\circ} \mathrm{C}$. The dried methanolic extracts obtained from each plant were air-dried then packed in glass bottles with proper labeling for future reference. The extracts were kept refrigerated and far away from light. Stock solutions were prepared in dimethyl sulphoxide (DMSO) at a concentration of $20 \mathrm{mg} / \mathrm{mL}$ and stored at $-20^{\circ} \mathrm{C}$ until use [20,21]. Finally, all the crude $80 \%$ methanolic extracts of each plant species were tested for antimycobacterial activity.

\section{Test organisms}

M. tuberculosis strains including (H37Rv, SIT777, SIT73, SIT26, SIT37, SIT1688, SIT336, SIT149, SIT53, and SIT54) and M. bovis strains (SB1176, SB1953 and SB0133)

Table 1 Medicinal plants used for antimycobacterial activity against Mycobacterium tuberculosis and Mycobacterium bovis strains

\begin{tabular}{|c|c|c|c|c|c|}
\hline Plant species & Family & Vernacular name & Parts used & Voucher specimen & Place of collection \\
\hline Ocimum basilicum & Lamiaceae & Basobila (Amharic (Amh)) & Seeds & AG-01 & AA (from market) \\
\hline Croton macrostachyus & Euphorbiaceae & Bisana (Amh) & Leaves & AG-02 & ALIPB compound \\
\hline Calpurnia aurea & Leguminosae & Digitta (Amh) & Roots & AG-03 & ALIPB compound \\
\hline Eucalyptus camaldulensis & Myrtaceae & Key bahirzaf (Amh) & Leaves & AG-04 & Harar \\
\hline Artemisia abyssinica & Asteraceae & Chikugn (Amh) & Leaves & AG-05 & Muka Turi \\
\hline
\end{tabular}


were obtained from TB laboratory of ALIPB and were used for evaluation of plants crude extracts.

\section{Preparation of Inoculum}

The isolates grown on Lowenstein Jensen medium (LJ) were sub-cultured in Middle Brook 7H9 broth supplemented with $\mathrm{OADC}$ at $37^{\circ} \mathrm{C}$ for $14-21$ days. The antimycobacterial activities of the extracts were evaluated against ten $M$. tuberculosis strains and three $M$. bovis strains by maintaining on Middle Brook 7H9 medium for about 14-21 days. The bacterial suspension was homogenized by vortex shakeup and the turbidity was adjusted in agreement with tube which is the scales of McFarland no. $1\left(3.2 \times 10^{6} \mathrm{cfu} / \mathrm{mL}\right)$. The inoculum was prepared diluting the bacterial suspension in the proportion of 1:20 in Middle Brook 7H9 broth medium. This diluted suspension $(100 \mu \mathrm{L})$ was used to inoculate each well of the plate [22].

\section{Anti-mycobacterial activity tests}

The antimycobacterial activity of $80 \%$ methanolic crude extracts of $O$. basilicum seeds, C. aurea root, C. macro stachyus, $A$. abyssinica and $E$. camaldulensis leaves were tested using the REMA. The susceptibility test was accomplished in 96 microplates (wells) using the resazurin as an indicator of cellular viability or growth inhibition. Working solutions of the tested extracts were diluted in Middle Brook 7H9 broth supplemented with OADC to obtain final sample concentrations that ranges from $0.78 \mu \mathrm{g} / \mathrm{mL}$ to $100 \mu \mathrm{g} / \mathrm{mL}$. Rifampicin was dissolved in DMSO and used as positive control drug and extracts/ drug free medium with strain suspensions were used as negative control. One hundred micro liters of Middle Brook 7H9 broth and the test inoculum were added to all testing wells, as well as to the drug/extract-free control wells. Then, one hundred micro liters working extract solutions were poured into the first well of each row from which two-fold dilution series were made through the micro plate column. Each extract concentration was assayed in duplicate. Each micro plate was then sealed with parafilm and incubated for $5-7$ days at $37^{\circ} \mathrm{C}$ in normal atmosphere. After the incubation period, $25 \mu \mathrm{L}$ of resazurin $0.02 \% \mathrm{w} / \mathrm{v}$ was added to each wells and reincubated at $37^{\circ} \mathrm{C}$ for $24 \mathrm{~h}$ for color development. The visual MIC was defined as the lowest drug/extract concentration that prevented the color change of resazurin reagent from blue to pink. Blue color in the well was interpreted as there is no mycobacterial growth and pink color was scored as growth occurrence [23,24].

\section{Determination of the Minimum Inhibitory Concentration (MIC)}

MIC was determined by using the REMA in 96 well micro titer plates. One hundred micro liters of Middle Brook
7H9 broth and M. tuberculosis and M. bovis strains were dispensed into all wells of a sterile 96-well microtitre plate. In the first column (no.1 well of all plate), one hundred micro liters of extracts were added to each first wells using a unique pipette for each extracts. The extracts were mixed thoroughly and fifty micro liters of extracts were transferred to well 2 to well 8 from which fifty micro liters were discarded. Well 9 up to well 12 were served as sterility and negative controls. The working solution of extracts $(100 \mu \mathrm{g} / \mathrm{mL})$ were diluted out across a 96well in a two-fold serial dilution to give final testing concentrations of $50,25,12.5,6.25,3.12,1.56$ and $0.78 \mu \mathrm{g} / \mathrm{mL}$. The same procedure was followed for rifampicin with the initial concentration of $32 \mu \mathrm{g} / \mathrm{mL}$ with subsequent dilution to the final testing concentrations $16,8,4,2,1,0.5,0.25,0.125$ and $0.06 \mu \mathrm{g} / \mathrm{mL}$. The plates were then incubated for $5-7$ days at $37^{\circ} \mathrm{C}$. After $7^{\text {th }}$ day, $25 \mu \mathrm{L}$ of resazurin was added to all wells and re-incubated overnight for development. The MIC was defined as the lowest concentration of the extracts/drugs that prevented a colour of resazurin to be changed from blue to pink (visual determination) [24-27]. According to Ramos [22], extracts were considered as active if they inhibited growth of mycobacterium at MIC $\leq 100 \mu \mathrm{g} / \mathrm{mL}$. Each extract was tested in duplicate against each strain.

\section{Data analysis}

The experimental results were computerized using EpiData version 3.1 and STATA version 11 statistical software for data entry and analysis purposes respectively. The MIC results were presented as mean value. The t-test was employed to test significance for the difference between $80 \%$ methanolic extract results of each plant and rifampicin against $M$. tuberculosis and M. bovis strains. All the data were analyzed at $95 \%$ confidence interval and considered as statistically significant.

\section{Ethical consideration}

The study was conducted after its approval by the Institutional Review Board of ALIPB. The test was done in the TB laboratory where the necessary protective wears such as respirators and gloves as well as safety cabinets were used, to minimize the risk of exposure to M. tuberculosis and M. bovis isolates.

\section{Results and discussion}

\section{Anti-mycobacterial activity of the crude extracts}

Crude $80 \%$ methanolic extracts of all the five plants, namely leaves of $C$. macrostachyus, seeds of $O$. basilicum, root of $C$. aurea, leaves of E. camaldulensis and $A$. abyssinica were screened for their antimycobacterial activity against $M$. tuberculosis strains (H37Rv, SIT777, SIT73, SIT26, SIT37, SIT1688, SIT336 ,SIT149, SIT53, SIT54) and M. bovis strains (SB1176, SB1953 and SB0133) 
by using REMA had showed antimycobacterial activity against $M$. tuberculosis and $M$. bovis strains with the mean MIC values ranging from 6.25 to $100 \mu \mathrm{g} / \mathrm{mL}$. Selective activity of five $80 \%$ methanolic crude extracts and rifampicin against all strains of $M$. tuberculosis and M. bovis were observed (Table 2).

\section{Minimum inhibitory concentration}

The MIC of the extracts was determined for their antimycobacterial activity using resazurin as an indicator for M. tuberculosis and M. bovis strains viability in 96-well microplates. The MIC of $80 \%$ methanolic extracts of root of $C$. aurea, seeds of $O$. basilicum, leaves of A. abyssinica, C. macrostachyus and E. camaldulensis ranged from $25-100 \mu \mathrm{g} / \mathrm{mL}$ and $12.5-75 \mu \mathrm{g} / \mathrm{mL}, 25-100 \mu \mathrm{g} / \mathrm{mL}$ and $25-50 \mu \mathrm{g} / \mathrm{mL}, 6.25-50 \mu \mathrm{g} / \mathrm{mL}$ and $12.5-50 \mu \mathrm{g} / \mathrm{mL}, 12.5-$ $100 \mu \mathrm{g} / \mathrm{mL}$ and $18.25-50 \mu \mathrm{g} / \mathrm{mL}$ and $6.25-50 \mu \mathrm{g} / \mathrm{mL}$ and $12.5-50 \mu \mathrm{g} / \mathrm{mL}$, respectively for M. tuberculosis and $M$. bovis strains. The investigation showed that leaves of $E$. camaldulensis extract was the most active against both M. tuberculosis and M. bovis strains (MIC 6.25$50 \mu \mathrm{g} / \mathrm{mL}$ ). The mean MIC results of $80 \%$ methanolic crude extracts of each plant showed significantly lower antimycobacterial activities in comparison to rifampicin for all strains (Table 2). Although all extracts were found less active than rifampicin, extracts of leaves of A. abyssinica and E. camaldulensis showed interesting antimycobacterial activity. However, reference strain of

\begin{tabular}{|c|c|c|c|c|c|c|c|}
\hline \multirow[t]{3}{*}{ Strains } & \multirow{3}{*}{$\begin{array}{l}\text { Strain } \\
\text { name }\end{array}$} & \multicolumn{5}{|c|}{ MIC $(\mu \mathrm{g} / \mathrm{ml})$} & \multirow[b]{3}{*}{ Rif } \\
\hline & & & & & & & \\
\hline & & $\mathrm{Ob}$ & $\mathrm{Ca}$ & $\mathrm{Cm}$ & $\mathrm{Aa}$ & Ec & \\
\hline H37Rv & MTB & 25 & 37.5 & 12.5 & 6.25 & 25 & 2 \\
\hline SIT777 & MTB & 50 & 50 & 100 & 50 & 25 & 4 \\
\hline SIT73 & MTB & 50 & 25 & 25 & 25 & 6.25 & 0.25 \\
\hline SIT26 & MTB & 75 & 50 & 25 & 50 & 50 & 2 \\
\hline SIT37 & MTB & 100 & 100 & 37.5 & 50 & 25 & 3 \\
\hline SIT1688 & MTB & 100 & 75 & 50 & 50 & 37.5 & 2 \\
\hline SIT336 & MTB & 100 & 37.5 & 100 & 37.5 & 50 & 1.5 \\
\hline SIT149 & MTB & 50 & 50 & 25 & 50 & 50 & 0.5 \\
\hline SIT53 & MTB & 75 & 75 & 25 & 50 & 50 & 0.25 \\
\hline SIT54 & MTB & 75 & 50 & 25 & 50 & 37.5 & 3 \\
\hline SB1176 & $\mathrm{MB}$ & 50 & 50 & 50 & 50 & 25 & 0.09 \\
\hline SB1953 & $\mathrm{MB}$ & 25 & 12.5 & 37.5 & 12.5 & 12.5 & 1 \\
\hline SB0133 & $\mathrm{MB}$ & 37.5 & 75 & 25 & 12.5 & 50 & 2 \\
\hline
\end{tabular}

$\mathrm{Ob}=$ Ocimum basilicum, $\mathrm{Ca}=$ Calpurnia aurea, $\mathrm{Cm}=$ Croton macrostachyus, $\mathrm{Aa}=$ Artemisia abyssinica, $\mathrm{Ec}=$ Eucalyptus camaldulensis, RIF $=$ Rifampicin, $\mathrm{MTB}=M$. tuberculosis, $\mathrm{MB}=\mathrm{M}$. bovis.
M. tuberculosis H37Rv, SIT73, SIT149, SIT149, SB1176 and SB1953 strains were comparatively the most susceptible strains to the extracts of the study plants with MIC $\leq$ $50 \mu \mathrm{g} / \mathrm{mL}$. In contrast, SIT37 and SIT336 strains were the most resistant to extracts as compared to other strains. The comparative mean MIC values of plant extracts and rifampicin against clinical isolates and reference strain of M. tuberculosis $H 37 R v$ and M. bovis strains is shown in (Table 2).

Despite intense hard work to control TB disease, it remains one of the global health problems claiming 1.4 million human lives per annum. Furthermore, in the worldwide up to 50 million people are said to be infected with drug-resistant forms of $\mathrm{TB}$ with about 500,000 cases of multi-drug resistant MDR-TB per a year [5). Thus, with the emergence of the drug-resistant strains of MTC, lengthy of therapy, which is very hurtful to a patient's health due to high levels of drug toxicity and its various adverse effects, the need to search for new effective anti-TB agents has become very necessary. Using medicinal plants for the treatment of TB offers a great hope to fulfill these needs because of their chemical diversity and they have been used for curing diseases for many centuries [11]. In addition, natural herbs continue to play a great significant role in the drug discovery and development of highly active antimycobacterial metabolites and they can be used as pure compounds or as crude materials [12].

In Ethiopia, many medicinal plants have been found which are used in the treatment of microbial infections including TB. It is our interest to report the anti-TB activity of these plants since these plants are reported from communities to treat $\mathrm{TB}$ and other respiratory infections. During ethnobotanical study these plants had been reported to possess antimicrobial activity. In the present study, the crude $80 \%$ methanol extracts of seeds of $O$. basilicum, root of $C$. aurea, and leaves of C. macrostachyus, A. abyssinica and E. camaldulensis showed promising antimycobacterial activity against M. tuberculosis and M. bovis strains. This may be due to the bioactive constituents, such as alkaloids, tannins, saponins, phenols, flavonoids and others that are present in the extracts $[28,29]$. Although the antibacterial activity of O. basilicum, C. aurea, C. macrostachyus, and A. abyssinica had been reported against other various pathogenic bacteria $[30,31]$, no report was found during a literature search against mycobacterium strains apart from ethnobotanical reports on these plants. Therefore, this investigation would be the first report on their anti-mycobacterial activities. The crude $80 \%$ methanolic extracts of leaves of $E$. camaldulensis exhibited the most antimycobacterial activity against both $M$. tuberculosis and $M$. bovis strains. This could be due the bioactive tannins and saponins present in the extracts. This report agrees 
with the previous reports of hexane, chloroform, methanol extracts of E. camaldulensis [32,33]. In Ethiopia, the present work demonstrates antimycobacterial properties of these plants having therapeutic value in the treatment of TB. However, it is generally recognized that the more antimycobacterial activity of extracts depends on their lipophilic nature and showed better activity $[20,34]$.

\section{Conclusions}

Even though this investigation supports the traditional medicinal usage in the Ethiopian community and the medicinal uses of these plants in different regions of Ethiopia; to obtain the most promising antimycobacterial activity and to conclude their anti-TB activity, these plants should be fractionated with less polar solvents. In addition, further investigations should focus on isolating chemical constituents responsible for pharmacological activities and identifying the compounds eliciting the activity observed in these plants.

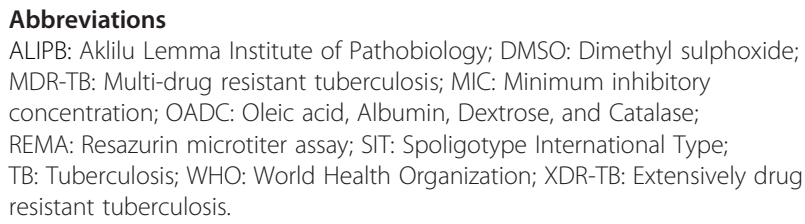

\section{Competing interests}

The authors declare that they have no competing interests.

\section{Authors' contributions}

AG designed the study, participated in data collection, analysis and drafted the manuscript. MG, participated in study design, data collection, analysis and write-up. GA, participated in study design, data collection, data analysis, interpretation and write-up of the manuscript and critically revised the manuscript. AW, involved in laboratory work, data analysis and interpretation. All authors read and approved the final manuscript. AG is the guarantor of the paper.

\section{Acknowledgements}

We are grateful to ALIPB, AAU for providing part of the necessary materials required for the study and financial support.

\section{Author details}

${ }^{1}$ Department of Medical Laboratory Sciences, College of Health and Medical Science, Haramaya University, Harar, Ethiopia. ${ }^{2}$ Aklilu Lemma Institute of Pathobiology, Addis Ababa University, Addis Ababa, Ethiopia.

Received: 22 August 2013 Accepted: 25 October 2013

Published: 29 October 2013

\section{References}

1. El ouarti A, Haouat AC, Sqalli H, Haggoud A, Ennabili A, Ibnsouda S, et al: Extra- and Intracellular Antimycobacterial activity of Arbutus unedo L. Afr J Microbiol Res 2012, 6:1283-1290.

2. Dye C: Global Epidemiology of Tuberculosis. Lancet 2006, 367:938-940

3. WHO: Global Tuberculosis Control: Epidemiology, Strategy and Financing. Geneva, Switzerland: WHO/HTM/TB/2009.411; 2009

4. WHO: Global Tuberculosis Report 2012. France: WHO/HTM/TB/2012; 2012:6.

5. WHO: Global Tuberculosis Control - Surveillance, Planning and Financing. Geneva, Switzerland: WHO/HTM/TB/2007.376; 2007.

6. Rivoire N, Ravololonandriana P, Rasolonavalona T, Martin A, Portaels F, Ramarokoto $\mathrm{H}$, et al: Evaluation of the Resazurin Assay for the Detection of Multidrug-resistant Mycobacterium tuberculosis in Madagascar. Int J Tuberc Lung Dis 2007, 11:683-688.

7. Aleme GA, Gebeyehu A: Clinical Improvement and Drug-adverse Effects among Patients Taking Anti-tuberculosis Drugs. Ethiopian J Health Biomed Sci 2010, 2:103-110.

8. Hannan A, Ullah MI, Usman M, Hussain S, Absar M, Javed K: Antimycobacterial activity of Garlic (Allium sativum) against Multi-drug resistant and non-Multi-drug resistant Mycobacterium tuberculosis. Pak J Pharm Sci 2011, 24:81-85.

9. Higuchi $C T$, Sannomiya M, Pavan FR, Leite SRA, Sato DN, Franzblau SG, et al: Byrsonima fagifolia Niedenzu Apolar Compounds with Anti-tubercular Activity. Evid-Based Complement and Altern Med 2008, 2011:1-5.

10. Gupta R, Thakur B, Singh P, Singh HB, Sharma VD, Katoch VM, et al: Anti-tuberculosis activity of Selected Medicinal Plants against Multi-drug resistant Mycobacterium tuberculosis isolates. Indian J Med Res 2010, 131:809-813.

11. Guzman JD, Gupta A, Evangelopoulos D, Basavannacharya C, Pabon LC, Plazas EA, et al: Anti-tubercular Screening of Natural Products from Colombian Plants: 3-Methoxynordomesticine, an Inhibitor of MurE Ligase of Mycobacterium tuberculosis. J Antimicrob Chemother 2010, 65:2101-2107.

12. Lawal TO, Adeniyi B, Wan AB, Franzblau SG, Mahady GB: In Vitro Susceptibility of Mycobacterium tuberculosis to Extracts of Uvaria Afzelli Scott Elliot and Tetracera Alnifolia Willd. Afr J Biomed Res 2011, 14:17-21.

13. Yirga G: Assessment of Indigenous Knowledge of Medicinal Plants in Central Zone of Tigray, Northern Ethiopia. African J Plant Sci 2010, 4:006-011.

14. Amsalu N: An Ethnobotanical Study of Medicinal Plants in Farta wereda. South Gondar Zone of Amhara Region, Ethiopia: MSc thesis, Addis Ababa University, Ethiopia; 2010

15. Yineger $\mathrm{H}$, Kelbessa $\mathrm{E}$, Bekele T, Lulekal E: Plants Used in Traditional Management of Human Ailments at Bale Mountains National Park, Southeastern Ethiopia. J Med Plants Res 2008, 2:132-153.

16. Tadeg H: Phytopharmaceutical Studies of Some Selected Medicinal Plants Locally used in the Treatment of Skin disorders. Ethiopia: MSc thesis, Addis Ababa University; 2004

17. Bekalo TH, Woodmatas SD, Woldemariam ZA: An Ethnobotanical Study of Medicinal Plants used by Local People in the Lowlands of Konta Special Woreda, Southern Ethiopia. J Ethnobiol Ethnomed 2009, 5:5-26.

18. Lulekal E, Kelbessa E, Bekele T, Yineger H: An Ethnobotanical Study of Medicinal Plants in Mana Angetu District, Southeastern Ethiopia. J Ethnobiol Ethnomed 2008, 4:4-10.

19. Seifu T: Ethnobotanical and Ethnopharmaceutical Studies on Medicinal Plants of Chifra District, Afar region. Northeastern Ethiopia: MSc thesis, Addis Ababa University, Ethiopia; 2004.

20. Mann A, Ibrah-im K, Oyewale AO, Amupitan JO, Okogun Jl: Antimycobacterial activity of Some Medicinal Plants in Niger State, Nigeria. African J Infect Dis 2009, 3:44-48.

21. Camacho-Corona M, Ramírez-Cabrera MA, González-Santiago O, Garza-Gonz ález E, Palacios I, Luna-Herrera J: Activity against Drug Resistant-Tuberculosis Strains of Plants used in Mexican Traditional Medicine to Treat Tuberculosis and Other Respiratory Diseases. Phytother Res 2008, 22:82-85.

22. Ramos DF, Leitão GG, Costa F, das N, Abreu L, Villarreal JV, Leitão SG, et al: Investigation of the Antimycobacterial activity of 36 Plant extracts from the Brazilian Atlantic Forest. Brazilian J Pharm Sci 2008, 44:669-674.

23. Martin A, Portaels F, Palomino JC: Colorimetric Redox-Indicator Methods for the Rapid Detection of Multidrug resistance in Mycobacterium tuberculosis: A Systematic Review and Meta-analysis. J Antimicrob Chemother 2007, 59:175-183.

24. Primm TP, Franzblau SG: Recent Advances in Methodologies for the Discovery of Antimycobacterial Drugs. Curr Bioactive Compounds 2007, 3:1-8.

25. Palomino JC, Martin A, Camacho M, Guerra H, Swings J, Portaels F: Resazurin microtiter assay plate: simple and inexpensive method for detection of drug resistance in mycobacterium tuberculosis. Antimicrob Agents Chemother 2002, 46:2720-2722.

26. Pavan FR, Sato DN, Higuchi CT, Santos ACB, Vilegas W, Leite CQF: In vitro anti-Mycobacterium tuberculosis activity of some Brazilian "Cerrado" plants. Braz J of Phar 2009, 19:204-206.

27. Ang CF, Mendoza MT, Bulatao WC: Evaluation of the Resazurin Microtiter Assay for Drug Susceptibility Testing of Clinical Isolates of Mycobacterium tuberculosis. Philipp J Microbiol and Infect Dis 2010, 39:59-65. 
28. Arya V: A Review on Anti-Tubercular Plants. Int J Phar Tech Res 2011, 3:872-880.

29. McCarthy E, Mahony MO: What's in a Name? Can Mullein Weed Beat TB Where Modern Drugs Are Failing? Evid-Based Complement and Altern Med 2011, 2011:1-7.

30. Nibret E, Wink J: Volatile components of Four Ethiopian Artemisia Species extracts and there in vitro Anti- Trypanosomal and Cytotoxic activities. Phytomedicine 2010, 17:369-374.

31. Hussien J, Teshale C, Mohammed J: Assessment of the Antimicrobial Effects of Some Ethiopian Aromatic Spice and Herb Hydrosols. Int $J$ Pharmacol 2011, 7:635-640

32. Lawal TO, Adeniyi BA, Idowu OS, Moody JO: In vitro activities of Eucalyptus camaldulensis Dehnh and Eucalyptus torelliana F. Muell against Nontuberculous Mycobacteria Species. Afr J Microbiol Res 2011, 5:3652-3657.

33. Lawal TO, Adeniyi BA, Adegoke AO, Franzblau SG, Mahady GB: In vitro Susceptibility of Mycobacterium tuberculosis to extracts of Eucalyptus camaldulensis and Eucalyptus torelliana and Isolated Compounds. Pharm Biol 2012, 50:92-98.

34. Coelho TS, Cantos JB, Bispo MLF, Gonçalves RSB, Lima CHS, da Silva PEA, et al: In vitro anti-mycobacterial activity of $(\mathrm{E})$ - $\mathrm{N}^{\prime}$ - (monosubstitutedbenzylidene) isonicotinohydrazide derivatives against isoniazid- resistant strains. Infect Dis Rep 2012, 4:e13.

doi:10.1186/1472-6882-13-291

Cite this article as: Gemechu et al:: In vitro Anti-mycobacterial activity of selected medicinal plants against Mycobacterium tuberculosis and

Mycobacterium bovis Strains. BMC Complementary and Alternative Medicine 2013 13:291

\section{Submit your next manuscript to BioMed Central and take full advantage of:}

- Convenient online submission

- Thorough peer review

- No space constraints or color figure charges

- Immediate publication on acceptance

- Inclusion in PubMed, CAS, Scopus and Google Scholar

- Research which is freely available for redistribution 